\title{
Programa Um Computador por Aluno: o acesso às tecnologias digitais como estratégia para a redução das desigualdades sociais
}

\author{
Adda Daniela Lima Figueiredo Echalar ${ }^{a}$ \\ Joana Peixoto ${ }^{b}$
}

\section{Resumo}

O presente artigo se origina de pesquisa que abordou o Programa Um Computador por Aluno (Prouca), compreendido como política pública para a inclusão digital via ambiente escolar que está alinhada a diretrizes econômicas internacionais de ordem neoliberal. Com base em documentos e entrevistas com 55 profissionais das nove escolas goianas contempladas com o Programa, observamos que o Prouca renova a utopia técnica de que a sociedade evolui qualitativamente com a aquisição de tecnologias de informação e de comunicação. Queremos demonstrar que os identificados problemas e deficiências na infraestrutura para a sua implantação, na gestão de seus processos e na formação dos professores não se constituem em aspectos pontuais, mas estruturantes deste Programa. Por esta razão, o seu mero reajuste ou adequação não são suficientes para equalizar as desigualdades sociais, conforme o propalado.

Palavras-chave: Tecnologias e educação. Políticas públicas. Prouca. Inclusão excludente.

\section{Introdução}

Desde 2003, o discurso governamental no Brasil situou a inclusão digital no campo dos direitos, do exercício da cidadania e do desenvolvimento social, ressaltando o caráter transformador das chamadas novas tecnologias (ECHALAR, 2015). Ela passou a ser considerada como um dos caminhos para a inclusão social, visto que possibilita aos cidadãos o uso de computadores e internet para receber

\footnotetext{
a Universidade Federal de Goiás. Goiânia, Goiás, Brasil.

b Instituto Federal de Educação, Ciência e Tecnologia de Goiás e Pontifícia Universidade Católica de Goias. Goiânia, Goiás, Brasil.
} 
e compartilhar informações, ter acesso a oportunidades de trabalho, participar de cursos profissionalizantes e oficinas (BRASIL, 2011).

No ano de 2005, foi criado o Programa Brasileiro de Inclusão Digital (PBID) com intuito de centralizar algumas das ações governamentais e coordenar as diferentes ações nascentes para a Política Nacional de Inclusão Digital (PNID). A base da PNID, a partir dessa gestão, possui um triplo eixo composto por renda, educação e tecnologias da informação e da comunicação, associando a inclusão digital à inclusão social, já que considera que o acesso a estas tecnologias favoreceria a melhoria da renda e o acesso à educação (CARVALHO, 2010).

Atualmente, o PBID é composto por 17 programas e projetos criados e mantidos pelo governo federal. No Programa Plurianual (PPA) de 2004-2007, o governo federal elegeu "crianças e escolas" como alvos prioritários de suas ações de inclusão digital. Além do Governo Eletrônico de Serviço de Atendimento ao Cidadão (Gesac), responsável pela conexão das escolas públicas à internet, as escolas se tornaram alvos diretos de quatro programas filiados ao Ministério da Ciência e Tecnologia (MCT) e ao Ministério da Educação (MEC): ProInfo Integrado, Programa de Implantação de Salas de Recursos Multifuncionais, Programa Banda Larga nas Escolas e o Programa Um Computador por Aluno (Prouca).

Em pesquisa realizada pelo Comitê Gestor de Internet no Brasil (CGI.BR) no período que vai de novembro de 2015 a junho de 2016, dados indicam que grande parte da população ainda não se encontra incluída digitalmente (NÚCLEO DE INFORMAÇÃO E COORDENAÇÃO DO PONTO BR, 2016). A exclusão se acentua mais ainda quando observamos o acesso à internet, considerando as diversas classes sociais. Por exemplo, verifica-se que, até o início de 2016, cerca de $50 \%$ da população brasileira teve acesso ao computador em casa com internet. Destes, apenas $47 \%$ das pessoas que constituem a classe social C e $13 \%$ dos indivíduos da classe $\mathrm{D}$ e $\mathrm{E}$ possuem esse recurso em casa ${ }^{1}$.

No Brasil, as iniciativas de inserção de tecnologias na educação e as políticas públicas que as ancoram se coadunam com as demandas econômicas e ideológicas dos países desenvolvidos, visando atender ao mercado no modelo de uma economia neoliberal. Este modelo tem difundido a inserção das tecnologias digitais na educação como condicionalidade para o financiamento de políticas sociais (BARRETO, 2012; EVANGELISTA, 2013; MAUÉS, 2009). Como afirma Sacristán (1996, p. 61):

\footnotetext{
Classes sociais definidas segundo Critério de Classificação Econômica Brasil (CCEB), pela Associação Brasileira de Empresas de Pesquisa (ABEP) e adotado no livro do Centro de Estudos sobre as Tecnologias da Informação e da Comunicação - Cetic (2016). Disponível em: <http://www.abep.org/Servicos/Download.aspx?id=07>. Acesso em: 16 jan. 2017.
} 
Os valores de justiça, equidade, dignidade humana, solidariedade e distribuição da riqueza e do capital cultural vão sendo substituídos pela preocupação pela eficácia, pela competitividade, pela "excelência", pela busca de resultados tangíveis, pelo ajuste às necessidades do mercado de trabalho e da economia, pela luta para dispor de melhores condições de saída do sistema educacional diante de um mundo do trabalho escasso, pela formação em destrezas básicas, pela necessidade de incorporar as tecnologias da informação, etc. (Grifo nosso).

Se considerarmos o percurso de construção do conceito de inclusão digital, veremos que este é tributário da economia capitalista e das políticas públicas propostas aos países denominados pobres ou em desenvolvimento. A definição de exclusão digital se dá em função de um retardo no acesso às tecnologias digitais, que toma como referência um determinado padrão de acesso e uso destas tecnologias. O seu oposto, a inclusão digital, também tem o mesmo padrão de referência: os chamados países em desenvolvimento que se caracterizam por um uso intensivo de tecnologias. Segundo esta lógica, o padrão deve ser reproduzido para o alcance do estágio ideal de desenvolvimento econômico (ECHALAR, 2015).

Todavia, dados da pesquisa da Organização para a Cooperação e Desenvolvimento Econômico-OCDE (OECD, 2015) sobre computadores, alunos e aprendizagem em diversos países asseveram o inverso da lógica supracitada, logo corroboram com o olhar proposto neste artigo:

Os resultados também mostram nenhuma melhoria apreciável no desempenho dos alunos em leitura, matemática ou ciência nos países que investiram pesadamente em TIC na educação. E talvez a descoberta mais decepcionante do relatório é que a tecnologia é de pouca ajuda para diminuir o fosso de competências entre estudantes favorecidos e desfavorecidos. Simplificando, garantindo que toda criança atinge um nível básico de proficiência em leitura e matemática parece fazer mais para criar igualdade de oportunidades em um mundo digital, do que pode ser conseguido por meio da expansão ou subsidiar o acesso a dispositivos e serviços de alta tecnologia (p. 3, tradução nossa).

Por esta razão, consideramos importante ficar atentos a esta definição de exclusão digital, que se baseia em uma visão econômica unilateral e inequívoca de progresso, adotando como padrão os equipamentos, as formas de uso e os tipos de serviço dos países desenvolvidos. Para Martins (2012, p. 26), a exclusão não é o contraponto da inclusão. Ela se refere ao conjunto de dificuldades, aos modos 
e problemas de uma inclusão excludente ${ }^{2}$ ou, como apresentada pelo autor, uma "inclusão precária e instável, marginal".

Tal definição coloca-se na rota de uma economia que gerou e continua gerando a exclusão que pretende superar (ECHALAR, 2015). Assim, a redução das desigualdades sociais não poderá decorrer de políticas de inclusão digital, mesmo que estas sejam geridas e implementadas com eficácia. Isto porque as desigualdades de acesso e de uso das tecnologias são, na verdade, o prolongamento de desigualdades econômicas e sociais pré-existentes.

Os programas governamentais partem do pressuposto de que as necessidades dos menos favorecidos são atendidas com a posse de um aparato digital que, por si só, garantiria a imersão na rede mundial de computadores. Tais programas "[...] não se comprometem, de fato, com as condições infra estruturais para a sua implantação, já que não a contextualizam às condições de cada região e não propõem a participação dos sujeitos envolvidos em sua implementação" (ECHALAR, 2015, p. 33).

Observamos um discurso marcado pela ideia de que o acesso e a aquisição de bens tecnológicos possibilitariam a melhoria do padrão de vida dos sujeitos dos países pobres e em desenvolvimento. Esse processo ilusório de elevação social por meio da aquisição de bens faz-se presente no ambiente escolar quando as políticas públicas são pensadas de maneira articulada aos objetivos da escola e da formação de seus professores.

Assim, analisaremos a implantação do Prouca no Brasil e no Estado de Goiás, a partir do tratamento da questão da inclusão digital via ambiente escolar como resultado de políticas públicas vinculadas aos organismos multilaterais em nosso país, os quais visam à manutenção da desigualdade social por meio de um processo de inclusão excludente.

A presente investigação se deu por meio de uma pesquisa exploratória e empírica, nas nove escolas contempladas pelo Programa em Goiás. Foi realizada, também, uma análise documental da política de implementação do Prouca, visando perquirir os processos lógico-históricos entre a realidade aparente e a concreta dessa política, por meio das particularidades das escolas goianas. Para tanto, pautamo-nos no materialismo histórico-dialético como aporte teórico capaz de nos fornecer base para melhorar a compreensão da realidade concreta.

2 Termo cunhado por Cury (2008). 


\section{Do UCA ao Prouca: o processo de implantação deste programa no Brasil}

Dentre os programas do governo federal de inclusão digital via ambiente escolar, o Projeto Um Computador por Aluno (Projeto UCA) foi proposto no Brasil em 2005, inspirado pelas ideias do programa da One Laptop Per Child (OLPC), que propõe a distribuição de um laptop para uso individual de crianças de países pobres ou em desenvolvimento.

O projeto foi criado pelo Decreto $n^{0}$ 6.300, de 12/12/2007 (BRASIL, 2007), prevendo ações que se inserem no Plano de Desenvolvimento da Educação (PDE) e integram-se ao Programa Nacional de Tecnologia Educacional (ProInfo). Os documentos apontam como pontos inovadores da proposição para a educação:

a) o uso do laptop em um ambiente que permita a imersão numa cultura digital;

b) a mobilidade de uso do equipamento, dentro e fora da escola;

c) a conectividade por meio de redes sem fio conectadas à internet;

d) e o uso pedagógico das diferentes mídias colocadas à disposição no laptop educacional.

Do momento da apresentação da proposta do Projeto ao governo brasileiro até sua implantação, foi instituído um Grupo de Trabalho de Assessoramento Pedagógico do UCA (Gtuca) com os objetivos de assessorar pedagogicamente a elaboração do documento básico do projeto e de realizar o acompanhamento e a avaliação das cinco escolas-modelo que compuseram a fase pré-piloto, chamada Fase I, de sua implantação no País.

O Gtuca foi composto por membros da Secretaria de Educação a Distância do Ministério da Educação (SEED/MEC) e por assessores pedagógicos de distintas instituições de ensino superior (IES) do Brasil.

Algumas instituições receberam a responsabilidade pelo "aspecto pedagógico" (BRASIL, 2009) do Programa, sendo elas: o Laboratório de Sistemas Integráveis (LSI) - USP, o Laboratório de Estudos Cognitivos (LEC) - UFRGS e o

\footnotetext{
OLPC é uma fundação mantida pela associação entre pesquisadores e industriais cujo objetivo proclamado é fornecer a todas as crianças dos "países do sul" um computador simples, robusto, com autonomia de uso desconectado da rede elétrica e suficientemente barato. A ideia propalada foi a de desenvolver um laptop a 100 dólares. Disponível em: <http://one.laptop.org/>. Acesso em: 20 jul. 2015.
} 
Laboratório de Interação Avançada (LIA) - UFSCar. Estas propuseram atividades, desenvolvendo softwares educativos e avaliando a adaptação das crianças aos laptops. Já o Centro de Referência em Tecnologias Inovadoras (Certi), Centro de Pesquisa Renato Archer (CenPRA) e o Serviço Federal de Processamento de Dados (Serpro) focaram as questões técnicas, como a elaboração de softwares de gerenciamento e a realização de testes de hardware e software.

O Projeto UCA, também denominado por Fase I ou Pré-Piloto, voltou-se para a implantação dos laptops em cinco escolas-modelo no país, nos municípios de Brasília (DF), Palmas (TO), Piraí (RJ), Porto Alegre (RS) e São Paulo (SP). Esta fase contou com 7.933 professores envolvidos no Programa e a produção de três cartilhas referentes ao Suporte Técnico - Banda Larga nas Escolas, Suporte ao Laptop Educacional e Cartilha do UCA (RNP), disponibilizadas pelo MEC em seu site ${ }^{4}$, que desde o início de 2015 está fora do ar.

Além dos computadores portáteis, deveriam ser adquiridos outros equipamentos que permitiriam o acesso à internet. Esses equipamentos deveriam garantir a conectividade e a mobilidade nos espaços escolares (sala de aula, pátio, laboratórios etc.), bem como nas residências de estudantes e professores. $\mathrm{O}$ acesso a esses laptops garantiria o início de um processo de inclusão digital de familiares e da comunidade em geral.

Ao longo do ano de 2009, foram feitos os trabalhos de avaliação e consolidação dos cinco experimentos, sendo que, em 2010, foi concluído o processo de licitação para a compra dos equipamentos.

Os relatórios de avaliação da fase pré-piloto foram destinados a apresentar o contexto da escola, a infraestrutura, a gestão da escola, bem como três estudos de caso de acordo com a IES que era responsável pela implantação, formação e avaliação. Eles estavam disponíveis no site do Programa para quatro das escolas-modelo da Fase I, já que a escola-modelo de Brasília não apresentou relatórios nem foi objeto dissertações.

O processo de avaliação é citado nos relatórios do governo como sendo "fruto da mobilização de voluntários, empresas e universidades para promoção de projetos educacionais através do uso das Novas Tecnologias da Informação e Comunicação"s. A Fundação Pensamento Digital foi contratada para fazer

\footnotetext{
4 Estava disponível em: <http://www.uca.gov.br>. Site fora do ar. Informações sobre o projeto UCA disponíveis em: <http://www.fnde.gov.br/portaldecompras/index.php/produtos/laptops-educacionais-prouca. Acesso em: 16 jan. 2017.
}

5 Disponível em: <http://www.pensamentodigital.org.br/?q=node/5>. Acesso em: 14 abr. 2014. 
a avaliação da Fase I. Em seu site, estão disponíveis a missão da Fundação, os parceiros, o corpo diretivo, os relatórios e os projetos.

O nome Projeto UCA foi modificado para Programa Um Computador por Aluno em 2010, quando se instaura a Lei $\mathrm{n}^{\circ} 12.249$, de 10 de junho de 2010, que o cria e o regulamenta. De acordo com o MEC/SEED (BRASIL, 2010a, p. 9), a intenção do governo federal com relação ao Prouca é implantar:

uma nova forma de utilização das tecnologias digitais nas escolas públicas, balizada pela necessidade de:

a) melhoria da qualidade da educação;

b) inclusão digital;

c) inserção da cadeia produtiva brasileira no processo de fabricação e manutenção dos equipamentos.

No momento da implementação do Prouca, fez-se a expansão do Programa a 300 escolas do País, passando à Fase II, ou também chamada por Piloto. Essa lei apresenta, em seu capítulo II, artigo 7, as finalidades do Programa, que são:

[...] promover a inclusão digital nas escolas das redes públicas de ensino federal, estadual, distrital, municipal ou nas escolas sem fins lucrativos de atendimento a pessoas com deficiência, mediante a aquisição e a utilização de soluções de informática, constituídas de equipamentos de informática, de programas de computador (softwares) neles instalados e de suporte e assistência técnica necessários ao seu funcionamento [...] (BRASIL, 2010b, s/p, grifo nosso).

O Termo de Referência (BRASIL, 2010c) desse programa para implantação e desenvolvimento dos projetos-piloto nas escolas públicas e para o uso pedagógico do laptop educacional conectado, ressalta que sua chegada às escolas das redes públicas deve ocorrer para fins de melhoria na qualidade da educação, inclusão digital e inserção do aluno na cadeia produtiva, no processo de fabricação e manutenção dos equipamentos.

Em janeiro de 2010, o consórcio CCE/Digibras/Metasys foi dado como vencedor do pregão $\mathrm{n}^{\mathrm{o}} 107 / 2008$ para o fornecimento de 150 mil laptops educacionais às 300 escolas públicas na Fase II do Programa. 
As Secretarias de Educação, Estadual ou Municipal, deveriam selecionar as escolas para receber os laptops, de acordo com os cinco critérios nacionais para o Programa (BRASIL, 2013, s/p, online):

1. Número de alunos e professores (em torno de 500 alunos e professores);

2. Estrutura da escola (deveriam possuir, obrigatoriamente, energia elétrica para carregamento dos laptops e armários para armazenamento dos equipamentos);

3. Localização das escolas (preferencialmente, deveriam ser pré-selecionadas escolas com proximidade a Núcleos de Tecnologias Educacionais - NTE - ou similares, Instituições de Educação Superior públicas ou Escolas Técnicas Federais. Pelo menos uma das escolas deverá estar localizada na capital do estado e uma na zona rural);

\section{Assinatura do termo de adesão [...];}

5. Anuência do corpo docente (para cada escola indicada, a Secretaria de Educação Estadual ou Municipal deverá enviar ao MEC um ofício, onde o(a) diretor(a) da escola, com a anuência do corpo docente, aprova a participação da escola no projeto.

O processo de implantação, acompanhamento e avaliação do Programa em cada escola ocorreu de forma hierárquica e sequencial, sendo organizado conforme Quadro 1. Identificamos os membros da SEED/MEC e do Gtuca, as IES Globais como o grupo de assessores pedagógicos do Programa. As IES locais se constituem em espaço dos docentes/pesquisadores universitários que, em parceria com as IES Globais, integram o grupo de formação e pesquisa. As Secretarias de Educação (SE), Núcleos de Tecnologia Estadual (NTE) e Núcleos de Tecnologia Municipal (NTM) são as equipes de formação responsáveis pela implantação do Programa junto às 300 escolas da Fase II do Programa.

Ainda no ano de 2010, foi lançado o Edital n $n^{\circ} 76 / 2010$ do Conselho Nacional de Desenvolvimento Científico e Tecnológico (CNPq) em parceria com a Coordenação de Aperfeiçoamento de Pessoal de Nível Superior (Capes) e a SEED/MEC, com o objetivo de selecionar propostas para apoio financeiro a projetos relacionados ao uso de laptops nas escolas participantes do Prouca. 
Quadro 1. Estrutura organizacional de implantação do Prouca no Brasil.

\begin{tabular}{|c|}
\hline $\begin{array}{l}\text { QUEM: } \\
\text { Membros da SEED/MEC e do Gtuca }\end{array}$ \\
\hline $\begin{array}{c}\text { Atribuições: } \\
\text { Assessoria pedagógica e elaboração do documento básico do projeto. } \\
\text { Acompanhamento e avaliação das escolas-modelo (Fase I de implantação). } \\
\text { Ação 1: Preparação da equipe de formação dos representantes do Gtuca nas IES Globais. }\end{array}$ \\
\hline$\nabla$ \\
\hline $\begin{array}{c}\text { QUEM: } \\
\text { Membros das IES Globais } \\
\text { (universidades que possuem assessores pedagógicos do Gtuca em seu corpo docente) }\end{array}$ \\
\hline $\begin{array}{l}\text { Atribuiç̃̃es: } \\
\text { Ação 2: Preparação da equipe de formação dos membros das IES locais, SE e NTE/NTM. }\end{array}$ \\
\hline$\nabla$ \\
\hline $\begin{array}{l}\text { QUEM: } \\
\text { IES locais (universidades que possuem docentes que, em parceria com as IES Globais, } \\
\text { integram o grupo de formação e pesquisa), SE, NTE e NTM }\end{array}$ \\
\hline $\begin{array}{l}\text { Atribuições: } \\
\text { Ação 3: Formação dos professores e gestores nas escolas (Fase II). }\end{array}$ \\
\hline$\nabla$ \\
\hline $\begin{array}{l}\text { QUEM: } \\
\text { A ser definido com secretarias e escolas locais }\end{array}$ \\
\hline $\begin{array}{l}\text { Atribuições: } \\
\text { Ação 4: Formação dos alunos-monitores }\end{array}$ \\
\hline$\nabla$ \\
\hline $\begin{array}{l}\text { QUEM: } \\
\text { Professores, gestores e alunos }\end{array}$ \\
\hline $\begin{array}{l}\text { Atribuições: } \\
\text { Execução das ações previstas (público-alvo final) }\end{array}$ \\
\hline
\end{tabular}

Fonte: Adaptado de Ministério da Educação e Cultura. UCA - Projeto um computador por aluno - Formação Brasil. Brasil (2009).

Com a extinção da SEED, no ano de 2011, o Programa foi alocado na Secretaria de Educação Básica (SEB), vinculada ao MEC. No ano seguinte, foram apresentados os 28 projetos aprovados pelo CNPq, perfazendo cerca de cinco milhões de reais de investimentos em pesquisas nas escolas contempladas pelo Programa ${ }^{6}$.

\footnotetext{
6 Disponível em: <http://www.cnpq.br/web/guest/chamadas-publicas?p_p_id=resultadosportlet_WAR_ resultadoscnpqportlet_INSTANCE_OZaM\&filtro $=$ encerradas\&detalha $=$ chamadaDetalhada\&exibe $=$ exibe \& idResultado=47-106-1296\&id=47-106-1296>. Acesso em: 16 jan. 2017
} 
No que tange à formação de professores, o Gtuca instituiu um material denominado por "Formação Brasil: projeto, planejamentos das ações/cursos", que apresenta as diretrizes dos cursos de formação: objetivos, carga horária, conteúdos, pressupostos pedagógicos, condições necessárias, estratégias de implementação e operacionalização da proposta formativa para o trabalho na modalidade 1:17. O período de dois anos foi considerado o tempo mínimo para que os educadores se capacitassem para trabalhar pedagogicamente com os recursos digitais, nessa proposta.

A formação dos docentes e dirigentes envolvidos com o Prouca aparece como um dos quatro pilares deste Programa (BRASIL, 2010a). Estudos de Marques (2009), Echalar (2015), Santos (2012; 2014) e Toschi (2014) apontam um processo desarticulado e com lacunas. Santos $(2012$, p. 9) salienta que o tipo de formação ofertada ao professor é "fator dificultador - muitas vezes impeditivo" para que eles possam promover a sua inclusão digital e a de seus alunos.

Observamos que o processo formativo proposto pelo Prouca se deu por meio de uma divisão de trabalho que distingue claramente quem concebe e quem executa. Organiza-se de maneira fragmentada e hierarquizada, conforme a divisão capitalista do trabalho em que a dimensão intelectual e a técnica cabem a indivíduos distintos (MARX; ENGELS, 2007). Tal fragmentação contribui para um processo de alienação (MARX, 2004) dos professores, os quais são colocados como meros executores de ações que, no entanto, possuem uma dimensão intelectual.

No documento formulado pela Câmara dos Deputados (BRASIL, 2008, p. 42) sobre a chegada da OLPC e a implementação do Projeto UCA, encontramos a afirmação da importância do "[...] acesso a recursos e ferramentas capazes de estimular a criatividade e a personalização de projetos de qualquer natureza" (grifo nosso). Esta postura determinista (PEIXOTO, 2015) - presente no discurso da OLPC e, também, no documento da Câmara dos Deputados - imputa ao computador a capacidade de criar, desenvolver e descobrir conhecimentos, aliando este benefício ao já propalado direito do cidadão de ser incluído no progresso econômico mundial.

As tecnologias são tomadas como elementos que possuem o poder e a autonomia de transformar a educação, através da alteração dos papéis dos sujeitos que as utilizam, como pode ser verificado no documento citado:

7 Modalidade 1:1 se refere a modalidade de um computador para um aluno. 
Nas escolas, as tecnologias digitais oferecem uma enorme diversidade de informações e permitem interatividade e colaboração. O crédito em seu potencial para a transformação da educação escolar baseia-se na aposta de que elas são uma poderosa ferramenta para mudar os papéis atualmente desempenhados por professores e alunos no processo de ensino-aprendizagem, ao viabilizar a autonomia do aprendize a atuação do professor como orientador (BRASIL, 2008, p. 25; grifo nosso).

É necessário o enfrentamento da complexidade teórica e prática na relação entre educação e as tecnologias, para que possamos superar explicações simplistas, o julgamento de práticas ou a imposição de normas aos professores, gestores e alunos.

Tentamos explicitar a necessidade de deslocar o tratamento da questão da inclusão digital, reafirmando a permanência de uma inclusão excludente. As relações da OLPC com o nosso governo revelam-se como uma proposta de acordos de "qualificação da educação brasileira" por meio do uso de laptops educacionais, conforme as orientações da Unesco e de outros órgãos internacionais por meio de uma política educacional que prioriza a economia em detrimento da pedagogia.

Do UCA ao Prouca, o percurso da inclusão digital via ambiente escolar no Brasil foi marcado por condicionalidades econômicas (Quadro 2). Tais marcas se refletem desde os aspectos operacionais de aquisição de equipamentos até o processo de formação de professores, deixando uma forte lacuna no que diz respeito ao seu fundamento pedagógico.

O Prouca revela uma articulação entre a política econômica global e as políticas de governo orientadas para o trabalho social no país. Essa articulação não almeja efetivamente a inclusão social, já que não busca solucionar a concentração de renda de sua população, mantendo a desigualdade social.

O discurso de inclusão digital presente nos documentos oficiais do Prouca evidencia um processo de inclusão excludente: não promove a superação de uma condição de alienação da classe trabalhadora já que esta não vivencia um acesso racional às tecnologias digitais. Isto pode ser explicado, dentre outras razões, porque o acesso ao aparato digital, no caso o laptop, nas escolas ou nos telecentros, não garante ou assegura as mesmas oportunidades de aprender e participar do processo de imersão digital do que tê-los em casa e com boa qualidade de internet. $\mathrm{O}$ acesso ao aparato digital, no caso o laptop, não garante ou assegura as mesmas oportunidades de aprender e participar do processo de imersão digital. 
Quadro 2. Síntese da historicidade da implantação do Prouca no Brasil e em Goiás.

\begin{tabular}{|c|c|}
\hline Mês. Ano & Do UCA ao Prouca \\
\hline jun. 2005 & $\begin{array}{l}\text { Negroponte e o educador Seymour Papert apresentam, em Brasília, a ideia do } \\
\text { laptop educacional ao Presidente Lula, que decide criar um Grupo de Trabalho } \\
\text { para avaliar a solução. }\end{array}$ \\
\hline jul. 2005 & $\begin{array}{l}\text { Formação de um grupo técnico composto por três institutos de pesquisa } \\
\text { (Certi, USP e CenPRA) para avaliar, do ponto de vista pedagógico e } \\
\text { tecnológico, a solução proposta pelo MIT. } \\
\text { Missão técnica formada por representantes ministeriais e membros dos } \\
\text { institutos de pesquisa discute, na sede do MIT em Boston/EUA, detalhes do } \\
\text { projeto OLPC. }\end{array}$ \\
\hline nov. 2005 & Criação do Programa Brasileiro de Inclusão Digital (PBID). \\
\hline $\begin{array}{l}\text { jul. } 2005 \text { a } \\
\text { jul. } 2006\end{array}$ & $\begin{array}{l}\text { Conclusão dos trabalhos do grupo técnico. } \\
\text { Implementação dos experimentos em escolas. } \\
\text { Entrada de novos fornecedores. }\end{array}$ \\
\hline fev. 2007 & $\begin{array}{l}\text { Formalização do Projeto Um Computador por Aluno por meio de documento } \\
\text { denominado Projeto-Base do UCA. }\end{array}$ \\
\hline mar. 2007 & $\begin{array}{l}\text { Criação de um Grupo de Trabalho formado por professores para definir as } \\
\text { diretrizes pedagógicas do UCA. }\end{array}$ \\
\hline $\begin{array}{l}\text { mar.-ago. } \\
2007\end{array}$ & $\begin{array}{l}\text { Três fabricantes de equipamentos (Intel, OLPC-Quanta e Encore) fazem } \\
\text { doações de máquinas para a realização de experimentos de uso de laptops } \\
\text { pelos alunos. } \\
\text { Início dos experimentos nas cinco escolas escolhidas para participar da Fase I } \\
\text { do Projeto. }\end{array}$ \\
\hline dez. 2007 & $\begin{array}{l}\text { O Projeto começa a integrar o Plano de Desenvolvimento da Educação (PDE) } \\
\text { e do Prolnfo - Decreto } \text { n }^{\circ} 6.300 \text {, de } 12 \text { de dezembro de } 2007 \text {. }\end{array}$ \\
\hline $\begin{array}{l}\text { jan.-dez. } \\
2008\end{array}$ & $\begin{array}{l}\text { Portaria da extinta Secretaria de Educação a Distância (SEED) n } 85 \text { de } 16 \text { de } \\
\text { junho de } 2008 \text { apresentou as finalidades do Gtuca. } \\
\text { Reuniões mensais do Gtuca para consolidação dos planos de formação, } \\
\text { avaliação e monitoramento do Projeto UCA. }\end{array}$ \\
\hline $\begin{array}{l}\text { jan.-dez. } \\
2009\end{array}$ & $\begin{array}{l}\text { Início dos trabalhos de avaliação e consolidação dos cinco experimentos } \\
\text { iniciais, inaugurados em } 2007 . \\
\text { Apresentação do projeto Preparando para Expansão: Lições da } \\
\text { Experiência-Piloto Brasileira na Modalidade um para um, financiado pelo BID. } \\
\text { Chegada dos laptops na Escola Municipal Celina L. G. Matos. } \\
\text { Início da formação aos docentes da Escola Prof. Lourenço Batista. }\end{array}$ \\
\hline dez. 2009 & $\begin{array}{l}\text { Publicada a Medida Provisória } n^{\circ} 472 / 09 \text {, de } 15 \text { de dezembro de 2009, que } \\
\text { trata, dentre outros assuntos, da criação do Programa Um Computador por } \\
\text { Aluno, bem como da instituição de um regime especial para a compra de } \\
\text { Computadores voltados ao uso Educacional (Recompe). }\end{array}$ \\
\hline jan. 2010 & $\begin{array}{l}\text { O consórcio CCE/Digibras/Metasys foi dado como vencedor do pregão } \\
\text { no } 107 / 2008 \text { para o fornecimento de } 150 \text { mil laptops educacionais a } \\
\text { aproximadamente } 300 \text { escolas públicas. Assim, conclui-se o processo de } \\
\text { licitação para a compra dos equipamentos, iniciado em dezembro de } 2008 \text {. }\end{array}$ \\
\hline jul. 2010 & $\begin{array}{l}\text { A Medida Provisória } n^{\circ} 472 / 09 \text {, vinculada ao PDE e ao Prolnfo, que cria o } \\
\text { Prouca é convertida na Lei } n^{\circ} 12.249 \text {, de } 10 \text { de junho de } 2010 \text {. }\end{array}$ \\
\hline
\end{tabular}

Continua 
Continuação

\begin{tabular}{|l|l|}
\hline jul. 2010 & $\begin{array}{l}\text { Do UCA ao Prouca - implementação do Programa em } 300 \text { escolas brasileiras. } \\
\text { Chegada dos laptops as seguintes escolas goianas: Escola Prof. Lourenço } \\
\text { Batista, Escola Estadual Prof. Marcilon Dorneles, Escola Municipal Jaime } \\
\text { Câmara e Escola Municipal Profa. Dolores Martins. }\end{array}$ \\
\hline dez. 2010 & $\begin{array}{l}\text { Foi lançado o Edital no 76/2010 do Conselho Nacional de Desenvolvimento } \\
\text { Científico e Tecnológico (CNPq) em parceria a Coordenação de } \\
\text { Aperfeiçoamento de Pessoal de Nível Superior (Capes) e a Secretaria de } \\
\text { Educação a Distância do Ministério da Educação (SEED/MEC), com o objetivo } \\
\text { de selecionar propostas para apoio financeiro a projetos relacionados ao uso } \\
\text { de laptops nas escolas participantes do Prouca . }\end{array}$ \\
\hline $\begin{array}{l}\text { Chegada dos laptops as seguintes escolas goianas: Escola Estadual Profa. } \\
\text { ano de }\end{array}$ & $\begin{array}{l}\text { Vandy de Castro Carneiro, Escola Municipal Jaime Câmara, Escola Estadual } \\
\text { Romeu Roque Ramos e Escola Estadual Aplicação de Tempo Integral. } \\
\text { Início da formação aos docentes nas escolas: Municipal Profa. Dolores Martins, } \\
\text { Estadual Romeu Roque Ramos, Estadual Profa. Vandy de Castro Carneiro e } \\
\text { Estadual Aplicação de Tempo Integral. }\end{array}$ \\
\hline $\begin{array}{l}\text { segundo } \\
\text { semestre } \\
2012\end{array}$ & Início da formação aos docentes na escola goiana Prof. Marcilon Dorneles. \\
\hline
\end{tabular}

Fonte: Echalar (2015).

\section{O Prouca nas escolas goianas}

O site do MEC não dispõe de documentos referentes à implantação do Prouca em Goiás. Por esta razão, para analisar tal processo, nos pautamos nos dados coletados em nossa pesquisa empírica, em artigos, teses e dissertações e em documentos disponibilizados no site do UCA.

A implementação do Prouca em Goiás ocorreu em sistemas de ensino diferentes (Estado e município), o que gerou formas e tempos distintos em seu processo de implantação, apesar de o formato do curso ser o mesmo para todo o Estado. O Programa foi implantado em 2010, em nove escolas de oito cidades goianas: Goiânia, Iporá, Jussara, Mundo Novo, Ouro Verde, Rio Quente, Santa Cruz de Goiás e Trindade.

Em 2010 o Prouca atendeu 217 professores e 3.945 alunos (BRASIL, 2013), fornecendo cerca de 4.500 laptops às nove escolas contempladas pelo Programa (Tabela). A IES Global que atuou em nosso Estado foi a Pontifícia Universidade Católica de São Paulo (PUCSP - IES Global) e a IES Local foi Universidade Federal de Goiás (UFG), por meio do Laboratório de Tecnologia de Informação e Mídia Educativas (LabTime). 


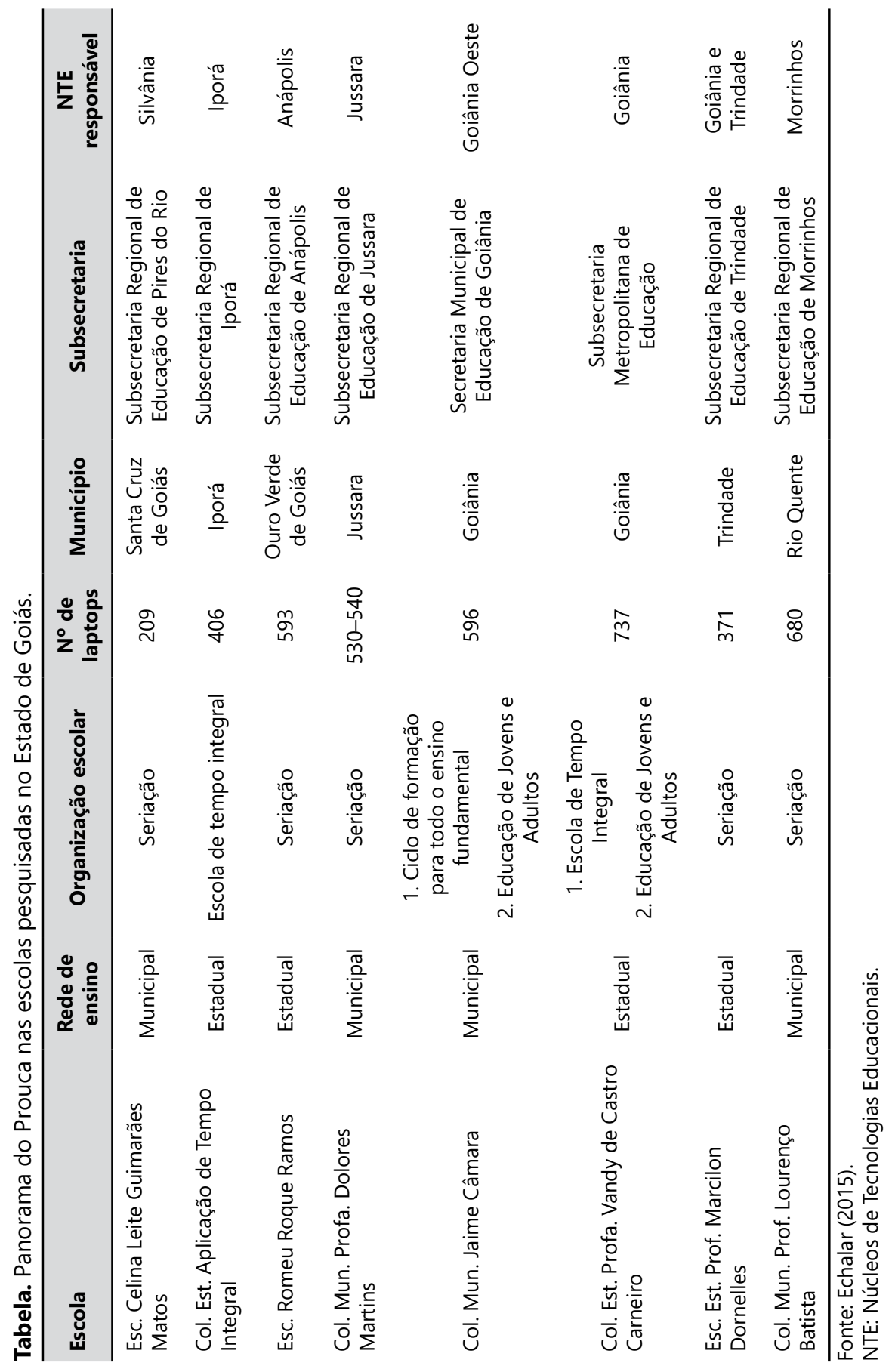


Cada escola esteve ligada ao NTE e subsecretaria de sua região, bem como aos profissionais do grupo do LabTime durante o processo de implementação do Programa e da formação docente. Quatro NTE não estão localizados no mesmo município da escola e todos estavam subordinados, hierarquicamente, ao grupo da IES local e este ao grupo de pesquisa da PUC-SP.

O processo de implantação do Prouca em Goiás se articula de forma coerente ao projeto de inclusão excludente já observado nas orientações da OLPC e do Prouca em nível nacional, pois trata-se de um programa focado na aquisição e distribuição de equipamentos, vinculado a um projeto internacional de educação, ditado e dirigido pelos organismos financiadores dessas políticas públicas educacionais.

\section{Considerações finais}

A análise preliminar do Prouca já indicava uma precária infraestrutura tecnológica e lacunas na formação de professores, embora tenha-se constatado também que os docentes fazem algum tipo de uso dos laptops em sala de aula ou em seus afazeres escolares.

Todavia, ao percorrer o processo lógico-histórico da implementação do Programa no Brasil, identificamos que é a lógica econômica que determina a concepção e a forma de implementação desse Programa. Em consequência disso, foi possível identificar a debilidade inerente à conceituação de inclusão e exclusão digital, bem como caracterizar a abordagem instrumental como fundadora do processo formativo docente.

Juntamente com Barreto (2012), Evangelista (2013) e Maués (2009), percebemos, com este estudo, que o Estado, ao fazer concessões e parcerias com os organismos internacionais, imputa ao docente um modo de pensar e agir baseado nas leis do mercado e do capital. Esta racionalidade se fundamenta muito mais na lógica do resultado e na reprodução de normas e leis do que no desenvolvimento intelectual autônomo.

A análise articulada dos documentos oficiais do Programa e dos dados coletados na ida às escolas goianas participantes do Prouca nos fez perceber o quão carente é a escola, sendo refém de frágeis projetos formativos, no que diz respeito à formação pedagógica de seus mestres e alunos.

Além disso, o curso oferecido pelo Prouca ocorreu em uma única vez em cada escola. Os professores que ingressaram na escola após o início do curso não puderam se integrar ao mesmo. $\mathrm{O}$ processo de alta rotatividade docente reduz 
gastos contratando profissionais temporários e promovendo a descontinuidade do processo pedagógico.

Em outras palavras, os identificados problemas e deficiências na infraestrutura para a implantação do Prouca, na gestão de seus processos e na formação dos professores não se constituem em aspectos pontuais, mas estruturantes deste Programa. Por esta razão, o seu mero reajuste ou adequação não são suficientes para equalizar as desigualdades sociais, conforme o propalado.

Sabemos que a inclusão excludente é inerente ao capitalismo e à política neoliberal. Todavia, acreditamos que é na resistência a essa forma precária de inclusão que podemos buscar a superação de uma sociedade tão injusta e desigual por meio da emancipação dos sujeitos.

Cabe ainda ressaltar que o mecanismo de inclusão excludente imputa aos professores a responsabilidade pela exclusão: os documentos do Programa explicitam, por exemplo, que cabe especialmente ao professor aproveitar essa oportunidade de incluir digitalmente os alunos sem levar em consideração os contextos formativos e as condições de trabalho dos docentes.

A complexa tarefa de avaliação de uma política educacional pública demanda um processo investigativo suficientemente amplo e aprofundado no sentido de colocar em questão o próprio papel que a universidade assume ao validar a formação continuada de professores em programas vinculados a políticas neoliberais. Não se trata apenas de compreender a realidade ou interpretar o mundo de várias maneiras, mas de oferecer meios para a resistência e o embate político, ou seja, de transformá-lo (MARX, 1987).

É vital a compreensão de que o processo de implementação não pode estar desarticulado de uma infraestrutura adequada nas escolas e que o processo formativo ofertado aos professores não pode ser pautado na fragmentação do trabalho, característica comum à economia capitalista.

Faz-se necessário também ouvir outros participantes do Programa, em suas distintas esferas hierárquicas, com intuito de avançar na compreensão do problema desta pesquisa. Cremos que a relação entre a academia, a pesquisa acadêmica e o processo de formação de professores da escola pública brasileira precisa ser repensado, para que a universidade consiga, por meio de suas pesquisas e ações formativas, cumprir seu papel social. Além de possibilitar a efetivação de um espaço de intelectuais preocupados e atuantes na construção de um país mais 
justo e igualitário, vislumbrando a luta pela educação pública de qualidade frente às designações dos organismos multilaterais como o BM, o FMI e a OCDE, pela profissionalização e valorização da docência, em contraposição ao processo alienante do mundo do capital.

O exame do processo de implantação do Prouca em Goiás e no Brasil permitiu explorar a noção de inclusão digital compreendendo-a como apologia de uma utopia digital que privilegia o acesso à informação em detrimento de uma política social. Em outras palavras, a promessa do Programa é típica de uma utopia tecnológica nutrida pelas transformações contemporâneas do capitalismo, pelo desenvolvimento do mercado de informações e também por uma dinâmica própria às discussões sobre as relações entre conhecimento, necessidades sociais e modernização.

Ao propor o provimento de um computador portátil para cada aluno da escola pública, o Prouca não se coloca apenas no rol de ações para a promoção de nova categoria de bens a serem integrados à panóplia do que é considerado indispensável para a vida moderna. Trata-se, também, de um projeto de remodelação social, que se apoia no ideal de um homem digital e autônomo, mas também flexível e reificado que atenderia ao mercado de trabalho.

Consideramos que a inclusão digital para inclusão social via ambiente escolar não favorece a melhoria da renda e o acesso à educação, a não ser que aceitemos que a resolução de questões técnicas, como o acesso ao equipamento, seja capaz de modificar o status que é fruto de uma construção histórica pautada nos princípios do capitalismo: domínio do dono da produção sobre o usuário e desigualdade como força motriz do sistema.

Assim, o distanciamento do projeto de modernização neoliberal que adota a inclusão digital como ferramenta para a inclusão social, implica em políticas inclusivas distintas daquelas em vigor. Trata-se da afirmação de políticas de Estado que implica em reordenamentos de ordem jurídica, econômica e política, que devem ser objeto de um próximo estudo. 


\title{
Prouca: access to digital technologies as a strategy for the reduction of social inequalities
}

\begin{abstract}
This article stems from a research addressing the training process of teachers in the context of the Program One Computer per Student (PROUCA), understood as a public policy for digital inclusion -through a school environment-, that is aligned with international economic guidelines of neoliberal order. Based on documents and interviews with 55 professionals from nine schools from Goiás, Brazil, that were part of the program, we observed that PROUCA renews the technical utopia that society evolves qualitatively with the acquisition of information and communication technologies. We want to demonstrate that the identified problems and deficiencies in the infrastructure for the program's implementation, in the management of its processes and in the training of the teachers are not specific but structuring aspects of this Program. For this reason, their mere readjustment or adequacy are not enough to equalize social inequalities, as has been said.
\end{abstract}

Keywords: Technologies and education. Public policy. Prouca. Excluding inclusion.

\section{Prouca: acceso a tecnologías digitales como estrategia para reducir las desigualdades sociales}

\section{Resumen}

En este articulo se deriva de la investigación que se ocupa de la formación procesa los maestros en el contexto del Programa de Uno Ordenador por Estudiante (PROUCA), entendida como una politica pública para la inclusión digital a través ambiente escolar que está alineado con las políticas económicas internacionales de orden neoliberal. Sobre la base de documentos y entrevistas con 55 profesionales de nueve escuelas de Goiás, Brasil, hayan adjudicado el programa, se observó que PROUCA renueva la utopía técnica que evoluciona la sociedad cualitativamente con la adquisición de tecnologías de la información y la comunicación. Queremos demostrar que los problemas y las deficiencias detectadas en la infraestructura para su implementación, la gestión de sus procesos y la formación del profesorado no constituyen aspectos especificos, pero la estructuración de este programa. Por esta razón, su mero reajuste o idoneidad no son suficientes para igualar las desigualdades sociales, ya que el cacareado.

Palabras clave: La tecnología y la educación. Políticas públicas. Prouca. Excluyendo la inclusión. 


\section{Referências}

BARRETO, R. G. A recontextualização das tecnologias da informação e da comunicação na formação e no trabalho docente. Educação \& Sociedade, v. 33, n. 121, p. 985-1002, out./dez. 2012. https://doi.org/10.1590/S0101-73302012000400004

BRASIL. Câmara dos Deputados. Um computador por aluno: a experiência brasileira. Brasília, DF, 2008.

. Decreto $N^{o} 6.300$, de 12 de dezembro de 2007. Dispõe sobre o Programa Nacional de Tecnologia Educacional - ProInfo. Diário Oficial da União. 13 dez. 2007.

Lei $N^{o} 12.249$, de 11 de junho de 2010. Institui o Regime Especial de Incentivos para o Desenvolvimento de Infraestrutura da Indústria Petrolífera nas Regiões Norte, Nordeste e Centro-Oeste - REPENEC; cria o Programa Um Computador por Aluno - PROUCA e institui o Regime Especial de Aquisição de Computadores para Uso Educacional - RECOMPE; prorroga benefícios fiscais; constitui fonte de recursos adicional aos agentes financeiros do Fundo da Marinha Mercante - FMM para financiamentos de projetos aprovados pelo Conselho Diretor do Fundo da Marinha Mercante - CDFMM; institui o Regime Especial para a Indústria Aeronáutica Brasileira - RETAERO; dispõe sobre a Letra Financeira e o Certificado de Operações Estruturadas; ajusta o Programa Minha Casa Minha VidaDisponível... Diário Oficial da União. 14 jun. 2010b.

. Ministério da Ciência e Tecnologia e Inovação. Secretaria de Ciência e Tecnologia para Inclusão Social. Programa de fomento à elaboração e à implantação de projetos de inclusão digital: informatização de escolas públicas. documento de referência para apresentação, habilitação e seleção de projetos. Brasília, DF, 2011.

. Ministério da Educação. PROUCA: Programa Um Computador por Aluno: critérios de seleção das escolas. Brasília DF, 2013.

. Ministério da Educação. Fundo Nacional de Desenvolvimento da Educação. Termo de referência. Brasília, DF, 2010c. Disponível em: $<\mathrm{ftp} / / / \mathrm{ftp}$. fnde.gov.br/web/editais_licitacoes/projeto_uca.pdf $>$. Acesso em: maio 2014.

. Ministério da Educação. Secretaria de Educação a Distância - SEED. Projeto Um Computador por Aluno: princípios orientadores para o uso pedagógico do laptop escolar. Brasília, DF, 2010a. Disponível em: <http://issuu.com/marinhos/ docs/projetouca_principios_versaoeditada > Acesso em: maio 2014. 
BRASIL. Ministério da Educação e Cultura. UCA-Projeto um computador por aluno: formação Brasil. Brasília, DF, 2009.

CARVALHO, A. M. G. Apropriação da informação: um olhar sobre as políticas públicas sociais de inclusão digital. 169 f. 2010. Tese (Doutorado em Ciência da Informação) - Universidade Estadual Paulista Júlio de Mesquita Filho, Marília, 2010.

CURY, C. R. J. A educação escolar, a exclusão e seus destinatários. Educação em Revista, n. 48, p. 205-22, dez. 2008. https://doi.org/10.1590/S0102-46982008000200010

ECHALAR, A. D. L. F. Formação docente para a inclusão digital via ambiente escolar: o PROUCA em questão. 147 f. 2015. Tese (Doutorado em Educação) - Pontifícia Universidade Católica de Goiás, Goiânia, 2015.

EVANGELISTA, O. Qualidade da educação pública: estado e organismos multilaterais. In: LIBANEO, J. C.; SUANNO, M. V. R.; LIMONTA, S. V. (Orgs.). Qualidade da escola pública: políticas educacionais, didática e formação de professores. Goiânia: Ceped, 2013. p. 13-46.

MARQUES, A. C. C. O projeto um computador por aluno - UCA: reações na escola, professores, alunos, institucional. 93 f. 2009. Dissertação (Mestrado em Educação) - Universidade Federal do Paraná, Curitiba. 2009.

MARTINS, J. S. Exclusão social e a nova desigualdade. São Paulo: Paulus, 2012.

MARX, K. Manuscritos econômico-filosóficos. São Paulo: Boitempo, 2004. . Teses sobre Feuerbach. São Paulo: Nova Cultural, 1987.

(Os pensadores).

MARX, K.; ENGELS, F. A ideologia alemã. São Paulo: Boitempo, 2007.

MAUÉS, O. C. A agenda da OCDE para a educação: a formação do professor. In: GARCIA, D. M. F.; CECILIA, S. (Orgs.). Formação e profissão docente em tempos digitais. Campinas: Alínea, 2009. v. 1.

NÚCLEO DE INFORMAÇÃO E COORDENAÇÃO DO PONTO BR. TIC domicílios 2015: pesquisa sobre o uso das tecnologias de informação e comunicação nos domicílios brasileiros. São Paulo: Comitê Gestor da Internet no Brasil, 2016. 
OECD. Students, computers and learning: making the connection. Paris, 2015.

PEIXOTO, J. Relações entre sujeitos sociais e objetos técnicos: uma reflexão necessária para investigar os processos educativos mediados por tecnologias. Revista Brasileira de Educação, v. 20, n. 61, p. 317-32, abr./jun. 2015. https://doi.org/10.1590/S1413-24782015206103

SACRISTÁN, J. G. Educação pública; um modelo ameaçado. In: SILVA, T. T.; GENTILI, P. (Org.). Escola S. A.: quem ganha e quem perde no mercado educacional do neoliberalismo. Brasília, DF: CNTE, 1996. p. 150-66.

SANTOS, G. L. Análise do projeto UCA (Um Computador por Aluno) na perspectiva da promoção da inclusão digital de professores da educação básica. In: ENCONTRO NACIONAL DE DIDÁTICA E PRÁTICA DE ENSINO - ENDIPE, 16., 2012, Campinas. Anais... S. n. t.

SANTOS, S. P. O programa um Computador por Aluno na visão dos jovens das escolas públicas de Goiânia. 238 f. 2014. Tese (Doutorado em Educação) - Universidade Federal de Goiás, 2014.

TOSCHI, M. S. Inclusão digital e social: conhecimento e cidadania. Revista de Educaçao Pública, v. 23, n. 53/2, p. 573-94, maio/ago. 2014.

\section{Informações das autoras}

Adda Daniela Lima Figueiredo Echalar: Doutora em Educação pela Pontifícia Universidade Católica de Goiás. Professora no Programa de Pós-Graduação em Educação em Ciências e Matemática da Universidade Federal de Goiás. Pesquisadora do Kadjót - Grupo Interinstitucional de Estudos e Pesquisas sobre as relações entre as Tecnologias e a Educação. Contato: docenciaonline2012@gmail.com

Joana Peixoto: Doutora em Ciências da Educação pela Universidade Paris 8. Professora no Mestrado em Educação para Ciências e Matemática do Instituto Federal de Educação, Ciência e Tecnologia de Goiás e colaboradora no Programa de Pós-Graduação em Educação da Pontifícia Universidade Católica de Goiás. Líder do Kadjót - Grupo Interinstitucional de Estudos e Pesquisas sobre as relações entre as Tecnologias e a Educação. Contato: joanagynn@gmail.com 